Spanbroek, N. (2005) 'Design profession and ageing in place' Australasian Journal on Ageing, June. Vol 24, Issue 2, Page 69-71.

\title{
The design profession and ageing in place
}

\section{Abstract}

Design Associations and the media have a responsibility to the community to promote good aesthetic and innovative universal housing design solutions. This could be encouraged through awards and publications that focus on excellence in universal design. Housing designers have a responsibility to both the present and future users, and need to be encouraged to integrate universal design features into the design of the home. 
Spanbroek, N. (2005) 'Design profession and ageing in place' Australasian Journal on Ageing, June. Vol 24, Issue 2, Page 69-71.

\section{The design profession and ageing in place}

Design Associations and the media have a responsibility to the community to promote good aesthetic and innovative universal housing design solutions. However, design professionals, architects and interior designer's gain design awards through their relevant associated bodies that illustrate contemporary housing design themes on the assumption it seems, that the users will never age nor have any disabilities. Design journals compound the issue of inadequate accessibility and lack of ease of habitation by promoting these home interiors as models for the future. Although the design professional is instructed by their client brief, there is also a responsibility beyond their client and visitors to include the wider community and future occupants.

To design responsibly need not be more costly. Good design is cost efficient when it occurs at the outset of a project as opposed to design modifications during, at completion of construction, or with home renovations. To assume the client will move on and be replaced by a fit and healthy occupant may be true for this decade, but what of the next? The future client may well be the ageing baby boomer, who will still seek out the beautiful aesthetic home, but will have expectations for accessibility, safety and independent living, '...prior research suggests that appropriate consideration of accommodation can be a critical factor in reduction of institutionalization and in promoting integration and inclusion'. [1]

The prospect of having to move from the family home because it does not support increasing physical frailties is a notion seldom considered by today's 
Spanbroek, N. (2005) 'Design profession and ageing in place' Australasian Journal on Ageing, June. Vol 24, Issue 2, Page 69-71.

ageing baby boomer generation, however this may well be the path Australian baby boomers are forced to take if they live in a home that is not suitable for their next stage of life - old age.

Australia's four million Baby Boomers born between 1946 -1964 is the largest ageing cohort Australia has ever experienced, and within this group there will be the largest number of people living alone. [2] The Australian Baby Boomers however, do not perceive themselves as growing old, and are uncomfortable about the prospect of ageing, nor will they want their homes to identify them by their age. Their reluctance to think about the future is understandable given the culture of the baby boomer, however 'what happens when health deteriorates enough to make living less than easy, but not bad enough to go to assisted-living or continued-care facilities'? [3] Given that older people generally want to maintain their independence for as long as possible, the design of the home becomes critical in allowing one to continue to live independently and this can only occur if the home is barrier free and supports physical frailties. Simple, and in some cases major renovations are required to prepare the home for an ageing occupant.

'Good housing design can orient, calm and enable support and independence. It plays a major role in determining the number of activities that a person can complete independently, and can directly assist social inclusion. So can poor housing design promote dependence and isolate people away from relationships, social experiences and community involvement. Poor housing design can increase stress and contribute to confusion, frustration and challenging behavior. In Australia demand will 
Spanbroek, N. (2005) 'Design profession and ageing in place’ Australasian Journal on Ageing, June. Vol 24, Issue 2, Page 69-71.

increase for appropriately designed, affordable housing as a result of property prices, shortage of metropolitan land and the current lack of appropriately designed and accessible housing stock.' [4]

As people age they progressively have trouble doing everyday domestic tasks in the home. Normal activities become a burden when one is required to reach and bend, climb stairs without handrails, turn door knobs with arthritic hands, negotiate hazardous changes in floor level with weakened eyesight. In addition built-in furniture and narrow walkways that hamper walking frames and other aids, appliances located at inappropriate heights, over-weight cabinetwork equipped with unsuitable hardware and floor surfaces with low friction coefficients, all impede independent living and can cause accidents in the home, one of the major causes of hospitalization amongst those 65 years of age and over. In Australia ' $73 \%$ of people aged between $65-80$ years of age either own their home outright or are purchasing them' [5] it therefore becomes critical that the home serves to support the frailties of ageing, not exacerbate them.

Historically the baby boomers are more mobile than previous generations, increasingly changing jobs and places of residence. Although age may not be a determining factor of how long one remains in the home, inappropriateness of the housing stock may well be a contributing factor. The challenge for the architectural and design fraternity is to design new houses that are beautiful, do not advertise the physical condition of the occupant, yet at the same time addresses the needs of this cohort and the broader community. 
Spanbroek, N. (2005) 'Design profession and ageing in place’ Australasian Journal on Ageing, June. Vol 24, Issue 2, Page 69-71.

Home designers today have a responsibility to address integrated universal design for the future. Journals and Design Associations must acknowledge and award good design by promoting aesthetic innovative solutions as templates for the future.

Key Points: Universal Design, Ageing in Place, Design fraternity.

1. Gibson, D \& Griew, R (2003) New Models and Approaches to Care. Paper prepared for 2020 A Vision for Aged Care in Australia. The Myer Foundation, November.

2. Australian Bureau of Statistics (1999) Household and Family Projections ABS Cat. No. 3236.0.

3. Heavens, A. (2004) Boomers Trend Toward "Age-In-Place" Housing, http://realtytimes.com/rtcpages/20011011_ageinplace.htm.

4. Bridge, C and Flynn, M. (2003) Home maintenance and modification information needs and evidence based practice solutions in NSW. National Housing Conference, Adelaide. Nov.

5. Howe, Anna L. (2003). Housing an older Australia: more of the same or something different? Keynote address to the Housing futures in an Ageing Australia Conference, Melbourne Sponsored by AHURi and The Myer Foundation, November. 